\title{
6
}

\section{COVID-19 E SUAS METÁFORAS: “ROTEIRO” OU “RODÍZIO”?}

\section{COVID-19 AND ITS METAPHORS: A "ROAD TRIP" OR A "RODÍZIO" DISCURSIVE STRATEGY?}

\author{
Maria Clotilde Almeida ${ }^{1}$ \\ Universidade de Lisboa
}

\author{
Rui Geirinhas ${ }^{2}$ \\ Universidade de Lisboa
}

\begin{abstract}
Resumo: O presente estudo cognitivo de índole qualitativa, ancorado na teoria da metáfora conceptual (LAKOFF; JOHNSON, 1980; GIBBS, 2017), assume como objetivo identificar os domínios-fonte de um leque de metáforas conceptuais usadas para representar a COVID-19, no contexto do discurso político. O facto de se tratar de doença infeciosa até agora desconhecida, com elevado risco de contágio e alguma taxa de mortalidade, promove a necessidade de a balizar semanticamente por via de figurações metafóricas e metonímias, tendo em vista a compreensão possível do fenómeno pandémico pelos cidadãos. A presente investigação visa traçar uma cronologia das metáforas de COVID-19 veiculadas pelos líderes políticos portugueses e pelo primeiro-ministro inglês, ao longo da vigência da pandemia, tomando como ponto de partida as imagens metafóricas de GUERRA. Coloca-se como questão de fundo se a evolução pandémica é acompanhada por uma sucessividade de figurações metafóricas dos líderes políticos, numa estratégia discursiva de "roteiro", ou se o discurso político incide recorrentemente sobre as metáforas de GUERRA, numa estratégia discursiva de "rodízio". Dado que se comprovou que os líderes políticos em questão enveredam pela estratégia discursiva de "roteiro", o nosso foco
\end{abstract}

${ }^{1}$ Endereço eletrônico: maria.almeida@campus.ul.pt

${ }^{2}$ Endereço eletrônico: rui.geirinhas@campus.ul.pt 
incide sobre as metáforas culturalmente marcadas (HIDALGO-DOWNING; KRALJEVIC-MUJIC, 2009).

Palavras-chave: COVID-19; figurações metafóricas; retórica política; metáfora e persuasão; metáforas culturalmente marcadas.

\begin{abstract}
The present cognitive-oriented paper profiled as a qualitative approach, anchored in the conceptual metaphor theory (LAKOFF; JOHNSON, 1980; GIBBS, 2017), and based upon the general postulate of the indissociability of meaning and physical, social and cultural experience, addresses the usage of COVID-19 conceptual metaphors and their source domains in political speech. The fact that COVID-19 is a highly contagious infectious disease with considerable mortality rates, unknown to mankind up to now, promotes the need of its semantic framing resorting to figurative metaphoric and metonymic language representation, with the purpose of enhancing people's understanding of it. So, our investigation is set to establish a time-line approach to COVID-19 metaphorical representations, taking metaphors of WAR as a point of departure. We have asked ourselves whether the pandemic evolution is accompanied by a succession of metaphorical figurative representations conveyed by the political leaders, following a "road trip" discursive strategy or whether the discourse of the political leaders is circularly organized around WAR metaphors, in the light of a "rodizio" communication strategy. Having arrived at the conclusion that the "road trip" discursive estrategy in political speeches about the COVID-19 by Portuguese political leaders and by the British Prime Minister clearly stands out, our focus relies upon the relevant role of culturallymarked metaphors (HIDALGO-DOWNING; KRALVEJIC-MUJIC, 2009).
\end{abstract}

Keywords: COVID-19; figurative language; political rhetoric; metaphor and persuasion; culturallyframed metaphors.

\title{
ALGUMAS CONSIDERAÇÕES TEÓRICAS, OBJETIVOS E METODOLOGIA
}

Traçamos como objetivo a análise qualitativa de um conjunto de figurações metafóricas sobre a COVID-19 emitidas por líderes políticos portugueses e pelo primeiro-ministro inglês, durante o período de vigência da pandemia até ao presente, com o objetivo de evidenciar diferentes estratégias políticas de persuasão no quadrante político português e inglês, numa perspetiva cronológica.

No quadro da classificação das metáforas quanto à sua natureza, é habitual estabelecer uma distinção entre metáforas conceptuais e metáforas discursivas. As primeiras são usadas extensivamente, mas de forma despercebida, afigurando-se transversais a diversas línguas e culturas (LAKOFF; JOHNSON, 1980), ao passo que as segundas são entendidas como projeções 
metafóricas de tipo dialógico, ou seja, ancoradas discursivamente (SEMINO, 2008).

Contudo, dado que o objetivo específico do presente estudo se centra nas figurações metafóricas dos líderes políticos enquanto formas de ação e de persuasão, em contexto comunicativo, com enfoque na clivagem cultural das figurações metafóricas usadas por líderes políticos portugueses que se preconizam diferentes das do primeiro-ministro inglês, Boris Johnson, a distinção entre metáfora conceptual e discursiva deixa de ser absolutamente relevante.

Partimos assim do pressuposto mais geral, estabelecido por Gibbs, na senda da obra de Lakoff e Johnson (1980), de que as figurações metafóricas são entendidas como performances em contexto. Por palavras deste autor "a metáfora é fundamentalmente algo que os seres humanos realizam, pelo que uma teoria da metáfora enquanto performance deveria ser consistente com o que sabemos acerca da forma de agir e de pensar do ser humano." (GIBBS, 2017, p. 330, tradução nossa) $)^{3}$.

Partimos ainda do pressuposto, também geral de que as metáforas constituem ferramentas argumentativas no discurso político usadas com objetivos persuasivos (CHARTERIS-BLACK, 2004, p. 19, tradução nossa): “Uma metáfora é uma representação linguística incongruente que tem o propósito de influenciar opiniões e juízos de valor mediante recurso à persuasão; este propósito é frequentemente oculto e reflete as intenções do falante num determinado contexto de uso" ${ }^{4}$.

3 "Metaphor is fundamentally something that that humans do and therefore, a theory of metaphor performance should be consistent with what is known about how human beings work".

4 "A metaphor is an incongruous linguistic representation that has the underlying purpose of influencing opinions and judgements by persuasion; this purpose is often covert and reflects speaker intentions within particular contexts of use." 
Em suma, partimos assim da hipótese de uma organização do discurso metafórico sobre a pandemia, ao longo do tempo, em "modo de roteiro", ou seja, mediante articulação sequencial de imagens metafóricas semanticamente diferentes. Na nossa ótica, este tipo de organização conceptual será motivado pelas crescentes exigências de persuasão do público relativamente às medidas de confinamento e afins adotadas pelos líderes políticos durante bastante tempo. Este "roteiro" de figurações metafóricas revelar-se-ia distinto de uma organização circular do discurso, em "modo de rodízio", ou seja, voltando sempre à metáfora de GUERRA para representar a forma de entender e lidar com o COVID-19.

Mais, à luz das representações metafóricas de doenças infeciosas da autoria de Hidalgo-Downing e Kraljevic-Mujic (2009), é nosso objetivo identificar algumas metáforas culturalmente adaptadas na base das quais é possível distinguir a clivagem cultural das imagens metafóricas dos políticos portugueses, com destaque para o primeiro-ministro e presidente da república portugueses, respetivamente António Costa e Marcelo Rebelo de Sousa, das do primeiroministro inglês Boris Johnson.

Passemos, assim, a caracterizar as metáforas culturalmente adaptadas. Por contraste com as metáforas conceptuais recorrentes, emergentes de mapeamentos praticamente universais, as metáforas culturalmente adaptadas foram definidas como “[...] introdutoras de uma modificação de registo baseada numa experiência sociocultural relevante."5 (HIDALGO-DOWNING; KRALJEVIC-MUJIC, 2009, p. 69).

A referida nomenclatura de metáforas culturalmente adaptadas decorre do enquadramento dos seus domínios-fonte nos "tipos naturais da experiência" que lhe dão origem, elencados por Lakoff e Johnson (1980). Para além das experiências com o nosso corpo de índole percetiva e motora, as nossas

\footnotetext{
5 "Culturally adapted metaphors introduce a register modification based on relevant sociocultural experience."
} 
capacidades mentais e reações emocionais etc., bem como das experiências de interação com o ambiente físico (mover-se, manipular objetos, comer etc.), existem as experiências de interação com outros seres humanos no seio da nossa cultura (no contexto das instituições sociais, políticas, económicas e religiosas). Como estes autores indicam (LAKOFF; JOHNSON, 1980), algumas destas experiências são universais, ao passo que outras sofrem alteração de cultura para cultura. Na mesma linha de pensamento, Semino (2008) assinala os domíniosfonte mais comuns no discurso político ocidental, a saber, PERCURSO/VIAGEM, CONTENTORES, DESPORTO, GUERRA e PESSOAS (i.e., personificação) que, como iremos ver, também se afiguram fundamentais na formulação das figurações metafóricas de COVID-19, no âmbito do discurso político. Por outro lado, procuraremos destrinçar um grupo de metáforas culturalmente marcadas no contexto político português e inglês, mas tendo em conta que, tratando-se de um fenómeno pandémico a nível global, as metáforas conceptuais usadas pelos políticos pelo mundo fora irão refletir estratégias de representação da doença pandémica idênticas.

\section{FIGURAÇÕES METAFÓRICAS DE COVID-19}

Tal como aconteceu com outras infeções hospitalares, como o MRSA (estafilococos áureos resistentes à meticilina), o cenário metafórico mais comum na representação desta doença contagiosa é o da GUERRA, mediante a ativação da metáfora conceptual LIDAR COM A DOENÇA É GUERRA (NERLICH; KOTEYKO, 2009). Neste cenário metafórico, os profissionais de saúde são os soldados que lutam contra esta doença infeciosa, com recurso a meios medicamentosos limitados.

A metáfora de GUERRA também está sendo muito utilizada para representar luta contra um inimigo desconhecido e muito contagioso, a COVID19 (SABUCEDO et al., 2020). Contudo, segundo estes mesmos autores, a metáfora 
da GUERRA restringe a caracterização de contágio e de luta contra a doença em meio hospitalar, pelo que tende a colocar em segundo plano o lado humano do sofrimento e da empatia, em contexto de doença pandémica.

No seu artigo Not soldiers but fire-fighters - metaphors and Covid-19, Semino (2020) também põe em causa a utilização sistemática das metáforas da GUERRA para representar a forma de lidar com o COVID-19. Argumenta esta autora que, ao personificarmos o vírus como um inimigo malévolo, criando uma ansiedade excessiva, estamos, por um lado, a legitimar medidas governamentais autoritárias e, por outro, a implicar que os que morreram não lutaram de forma eficaz contra o vírus. É assim preferível representar o fenómeno pandémico sob a égide da ação dos bombeiros que vão realizando a sua ação de dar conta de situações de incêndio durante um determinado período de tempo.

Esta perspetiva metafórica é a que melhor se coaduna com a metáfora DOENÇA INFECCIOSA É UMA VIAGEM (HIDALGO-DOWNIN; KRALJEVICMUJIC, 2009), sinalizando metaforicamente a forma de lidar com a doença, tendo por base uma viagem prolongada no tempo, inspirada na metáfora conceptual $\mathrm{A}$ VIDA É UMA VIAGEM (LAKOFF; JOHNSON, 1980), OS DOENTES e OS PROFSSIONAIS DE SAÚDE SÃO OS VIAJANTES, OS AVANÇOS E RECUOS NA CURA DO DOENTE SÃO OS OBSTÁCULOS NA VIAGEM e a CURA DO DOENTE É O FIM DA VIAGEM.

\section{METÁFORAS PROFERIDAS NO CENÁRIO POLÍTICO PORTUGUÊS}

\section{Metáforas de GUERRA e de VIAGEM}

As representações metafóricas usadas pelo Presidente da República, Marcelo Rebelo de Sousa, assinalam a pandemia como uma GUERRA, domínio conceptual muito produtivo e eficaz, conforme já referido anteriormente, mas também como processo que implica por parte das autoridades a definição de uma estratégia de atuação com vista a alcançar metas específicas. $\mathrm{O}$ exemplo de um 
excerto das suas declarações ao jornal Correio da Manhã (2020) ilustra bem a metáfora complexa COMBATE À PANDEMIA É GUERRA/COMBATE À PANDEMIA É UMA VIAGEM, quando afirma: “o combate tem corrido muito bem $[\ldots]$, mas tal não quer dizer que se chegou ao fim do caminho". Esta formulação metafórica complexa articula sequencialmente a metáfora da GUERRA com a metáfora da VIAGEM, ao vislumbrar uma trajetória de combate ainda em curso, ou seja, que ainda não chegou ao fim do percurso. Esta metáfora é inspirada na metáfora A VIDA É UMA VIAGEM, sendo uma das metáforas mais produtivas no discurso de tomada de posse de Marcelo Rebelo de Sousa, conforme evidenciado na investigação de Geirinhas (2020).

António Costa, primeiro-ministro português, na fase em que anuncia a existência de uma vacina de combate à pandemia, ainda que reconhecendo desconhecer o momento em que deverá surgir, afirma: “Há uma luz ao fundo do túnel, só não sabemos a extensão do túnel" (SIC NOTÍCIAS, 2020). Desta forma, dá corpo à metáfora conceptual, ancorada no esquema imagético PERTOLONGE: VACINA CONTRA O COVID-19 EM PERSPETIVA É LUZ AO FUNDO DO TUNEL que se configura na confluência conceptual entre CURA PARA A VACINA É UMA VIAGEM (num túnel)/CURA PARA A VACINA É UMA LUZ (ao fundo do túnel).

\section{Metáfora MARÍTIMA}

Também António Costa recorre a representações metafóricas impactantes na sua comunicação a propósito das decisões políticas tomadas em contexto pandémico, nomeadamente no apoio à economia, referindo: “Não há boias que nos ajudem [...]" (VISÃO, 2020). A figuração metafórica acima remete para a metáfora MEDIDAS ECONÓMICAS SÃO BOIAS DE SALVAMENTO, foca-se na necessidade de relevar a urgência da ação de socorrer a economia e de reconhecer a incapacidade do Estado para fazer face a todas as dificuldades económicas e sociais decorrentes da pandemia do COVID 19. 
Metáforas de CATÁSTROFE NATURAL/ACIDENTE GEOGRÁFICO

Ainda na comunicação política do primeiro-ministro português, identificamos um conglomerado de duas metáforas de índole diferente no excerto comunicativo abaixo: “O objetivo é evitar um pico muito acentuado. Temos um tsunami pela frente [...]" (VISÃO, 2020). O ponto mais alto da pandemia é veiculado por uma metáfora terminológica cristalizada nas ciências médicas. O ponto mais alto da pandemia é representado pelo ponto mais alto de uma montanha, logo EVOLUÇão DA PANDEMIA É ACIDENTE GEOGRÁFICO, pressupondo a correlação quantidade/verticalidade expressa pela metáfora primária MAIS É EM CIMA (LAKOFF; JOHNSON, 1980). A segunda metáfora conceptual que integra o encadeamento textual visiona metaforicamente a pandemia como uma catástrofe natural avassaladora, o que a torna incontrolável para o ser humano. Por esta imagem metafórica se infere que esta crise pandémica não é passível de ser associada a um agente responsável pelo seu desencadeamento.

Metáforas de FICÇÃO

António Costa recorre ao domínio-fonte da FICÇÃO, muito usado como domínio-fonte no universo jornalístico desportivo português (ALMEIDA et al., 2013), mas de sinal contrário, quando afirma: “O Estado não tem uma varinha mágica para resolver os problemas de todos. Gostava de ter uma bola de cristal e poder dizer como vamos estar em setembro" (VISÃO, 2020). A construção argumentativa do discurso do primeiro-ministro português é, pois, estruturada com base em domínios que radicam no conhecimento sociocultural dos contos 
de fadas $^{6}$ e suportada conceptualmente na representação metafórica POLÍTICA NÃO É FICÇÃO.

Metáforas de RELIGIÃO

Considerámos na categoria das metáforas culturalmente marcadas as Metáforas de RELIGIÃO, igualmente recorrentes no discurso do jornalismo português, com destaque para o jornalismo desportivo, que são construídas pela sua negação dos fenómenos milagreiros. Conforme se vislumbra abaixo, as palavras do primeiro-ministro, António Costa, desmistificam o eventual desaparecimento da pandemia por recurso à metáfora DESAPARECIMENTO DE COVID-19 NÃO É MILAGRE: “Não se pode dizer simultaneamente que Portugal enfrenta a maior crise económica de sempre e esperar que essa crise desapareça amanhã, por milagre, se a COVID-19 desaparecer."(PÚBLICO, 2020).

Esta perspetiva contrapõe a uma visão religiosa tradicional da resolução miraculosa de todos os problemas nacionais, inclusivamente a crise pandémica, atribuída a uma intervenção divina, o combate à pandemia levado a cabo pela ciência, em conjugação com as medidas políticas de regulação dos contatos e de proteção física dos sujeitos no espaço público impostas pelo governo português.

\section{METÁFORAS PROFERIDAS NO CENÁRIO POLÍTICO INGLÊS}

\section{Metáforas de GUERRA}

As representações metafóricas de GUERRA usadas por Boris Johnson servem como domínio-fonte das metáforas dos desenvolvimentos científicos em marcha para o combate à COVID-19. O primeiro-ministro inglês, no início da pandemia, pronunciou-se da seguinte forma: "temos de agir como um governo em tempo de guerra para proteger a economia"7 (THE GUARDIAN, 2020,

${ }^{6}$ Hidalgo-Downing e Kraljevic-Mujic (2009) aludem ao universo sociocultural do mundo dos contos de fadas ao identificarem a metáfora AN INFECTIOUS DESEASE IS A SLEEPING MONSTER.

7 "we must act like a wartime government to protect the economy". 
tradução nossa). Contudo, muito recentemente, B. Johnson utiliza a imagem "a trombeta distante da cavalaria científica"8 (THE GUARDIAN, 2020, tradução nossa) no discurso político abaixo: “Temos vindo a falar há muito tempo, ou seja, eu tenho-o feito, acerca do soar distante da trombeta da cavalaria científica. E hoje o som da trombeta é mais audível, mas ainda é um pouco distante." 9 (THE GUARDIAN, 2020, tradução nossa). Nesta imagem, os agentes científicos, metonimicamente representando as descobertas científicas, são conceptualizados metaforicamente como a ala de cavalaria do exército, considerada como de elite pelos britânicos. Estas descobertas da "cavalaria científica" são anunciadas pelo soar de uma trombeta ao longe, mas que em tempos mais recentes se encontra cada vez mais perto. Observe-se assim que esta metáfora complexa decorre do conglomerado metafórico-metonímico, tendo por base o esquema imagético PERTO-LONGE.

Metonímia: COMUNIDADE CIENTÍfICA ESTÁ POR DETRÁS DE DESCOBERTAS CIENTÍFICAS;

Metáfora culturalmente marcada 1: CAVALARIA É COMUNIDADE CIENTÍFICA;

Metáfora culturalmente marcada 2: SOAR DA TROMBETA É ANÚNCIO DISTANTE;

Metáfora culturalmente marcada 3: SOAR DA TROMBETA É ANÚNCIO MAIS PERTO.

Registe-se que esta imagem é claramente orientada para um público que cultiva a tradição militar da cavalaria, como é o caso do sistema militar britânico.

Metáforas de MÁQUINA

8 "Distant bugle of the scientific cavalry".

9 "We have talked for a long time, or I have, about the distant bugle of the scientific cavalry coming over the brow of the hill. And tonight that toot of the bugle is louder. But it is still some way off". 
O segundo par de figurações metafóricas tem enfoque na necessidade de persuasão dos britânicos acerca do imprescindível lockdown da população. Na primeira figuração metafórica em análise neste ponto, Boris Johnson afirma que as medidas de confinamento que entraram em vigor em julho de 2020 podiam sofrer alterações e voltar a existir restrições regionais. “Tal como acontece noutros países, haverá surtos repentinos que devem ser combatidos com medidas locais. E não hesitaremos em pôr o pé no travão e reintroduzir restrições mesmo a nível nacional, se tal for necessário"10 (THE SUN, 2020, tradução nossa). Neste exemplo, as restrições usadas no combate à propagação do COVID-19 são representadas como travões de um veículo, ou seja, a figuração metafórica é que o vírus é um veículo que está descontrolado, a alta velocidade. Tendo em conta que um veículo se move no espaço, foi usada uma metáfora estratégica VIRUS É MÁQUINA EM MOVIMENTO, que tem por base a metáfora conceptual primária DOENÇA É VIAGEM NO ESPAÇO (A ALTA VELOCIDADE). Assim, a deslocação rápida constitui um elevado perigo de vida para a população britânica, pelo que é necessário parar esta máquina em movimento, mediante um processo de travagem: "pôr o pé no travão"11.

Na segunda figuração metafórica, Boris Johnson, no final de julho de 2020, afirma haver um aumento muito significativo de casos positivos de COVID-19 e, como tal, as restrições não iriam diminuir no início de agosto, como tinha sido planeado inicialmente. Como tal, o primeiro-ministro britânico afirma: “Com os números a subir, a nossa avaliação da situação é de que devemos pôr o pé no travão para manter o vírus sob controlo"12 (EXPRESS, 2020, tradução nossa). Na ótica de Boris Johnson, é necessário utilizar os travões, de modo a tentar travar a

10 "Like in other countries, there will be flare ups for which local measures will be needed. And we will not hesitate to apply the brakes and reintroduce restrictions even at national level, even if required".

11 "Apply the brakes".

12 "With those numbers creeping up, our assessment is that we should squeeze that brake pedal... in order to keep the virus under control". 
deslocação rápida do vírus pela população e impedi-lo de prosseguir viagem. Assim sendo, a metáfora conceptual primária de base aqui é a mesma da figuração anterior, DOENÇA É VIAGEM NO ESPAÇO (A ALTA VELOCIDADE) e a figuração metafórica VIRUS É VEÍCULO MOTORIZADO EM MOVIMENTO.

\section{Metáfora de DESPORTO}

É um facto que Boris Johnson não se coíbe de usar também um tipo particular de metáforas de desporto, quanto a nós, de cunho marcadamente cultural, para persuadir o povo inglês acerca das suas opções políticas na resolução dos problemas cadentes do país. Uma das metáforas usadas por Boris Johnson anteriormente, a propósito do Brexit, é A LUTA POLÍTICA É UM COMBATE DE WRESTLING (CHARTERIS-BLACK, 2019, p. 171). Esta metáfora conceptual já foi anteriormente identificada por R. Gibbs como uma alegoria (GIBBS, 2015). Segundo este autor, as alegorias possuem uma carga simbólica elevada que convida a uma simulação corporizada por parte do público, centradas em experiências táteis e cinestésicas. Boris Johnson segue esta mesma linha de pensamento para representar o combate ao COVID-19, muito recentemente, em 11 de novembro de 2020, na ABC NEWS, como um combate de boxe, corpo a corpo, e de extrema violência. Desta forma, sinalizam as notícias recentes acerca do programa da vacina Pfizer como “duas luvas de boxe para esmurrar a doença"13(ABC NEWS, 2020). Assim, os progressos da ciência no combate à pandemia, representada metonimicamente pela vacina contra o COVID-19 da Pfizer, são configurados metaforicamente pela imagem de duas luvas de boxe para "esmurrar repetidamente" a doença.

Metáfora culturalmente marcadas: COMBATE À DOENÇA É COMBATE DE BOXE;

13 "Two boxing gloves to pummel the disease". 


\section{Metonímia: VACINA É COMUNIDADE CIENTÍFICA;}

Metáfora culturalmente marcada: VACINA É DUAS LUVAS DE BOXE.

\section{Metáforas de VIAGEM e de CONTENTOR}

Neste mesmo discurso de 11 de novembro, em que Boris Johnson declara medidas de confinamento no território britânico, até 2 de dezembro, também anuncia a boa nova da vacina de combate à pandemia, através da qual se poderão ultrapassar estes momentos difíceis, muito em breve, recorrendo à expressão idiomática de cunho metafórico "a light at the end of the tunnel". Contudo, contra-argumenta com a expressão idiomática de cunho metafórico "not to be out of the woods", construída na base do esquema do contentor DENTRO/FORA: "[...] já se vislumbra uma luz no fundo do túnel", "mas ainda não estamos fora de perigo"14 (ABC NEWS, 2020, tradução nossa).

Dá assim corpo à metáfora conceptual, ancorado no esquema imagético PERTO-LONGE: VACINA CONTRA O COVID-19 EM PERSPETIVA É LUZ AO FUNDO DO TUNEL que se configura na confluência conceptual entre CURA PARA A VACINA É UMA VIAGEM (num túnel)/CURA PARA A VACINA É UMA LUZ (ao fundo do túnel). Contudo, nas palavras de Boris Johnson; "we're not out of the woods", ou seja, ainda não estamos fora do perigo, ou seja, ainda estamos no interior do espaço da doença e temos ainda hipótese de sermos contagiados com a COVID-19.

\section{NOTAS FINAIS}

Embora apenas se trate de uma amostragem reduzida de metáforas de COVID-19, ficou bem patente que a estratégia discursiva do "roteiro" de metáforas evidencia que, ao longo da pandemia, os discursos dos líderes políticos portugueses e do primeiro-ministro inglês se afastam da METÁFORA DA

14 "[...] there is a light at the end of the tunnel", "but we're not out of the woods yet". 
GUERRA, abandonando o discurso de "rodízio" sobre a pandemia. Ao enveredarem por uma série de metáforas suportadas por outros domínios da experiência, algumas das quais se afiguram culturalmente marcadas, encontraram novos caminhos metafóricos para veicular um discurso persuasivo, destinado a convencer a população a aceitar as medidas de confinamento profilático.

A elaboração das metáforas culturalmente marcadas é particularmente saliente no caso das figurações metafóricas de Boris Johnson, que recorre a imagens metafóricas caras ao universo cultural britânico que radicam no "som da trombeta da cavalaria científica" ou como no "combate com duas luvas de boxe", em referência metafórica à vacina de Pfizer que permitirá combater eficazmente a pandemia. Em consequência, ele já antevê que "LIDAR COM A PANDEMIA É LUZ AO FUNDO DO TÚNEL “a light at the end of the tunnel”, embora ainda não estejamos fora de perigo ("not out of the woods").

No caso do presidente da República português, Marcelo Rebelo de Sousa, a figuração metafórica complexa sobre a COVID-19 envolve os domínios-fonte da GUERRA e da VIAGEM. Já o primeiro-ministro português António Costa, envereda, nos seus discursos políticos, pela construção de metáforas de COVID19 ancoradas no domínio-fonte do MAR, e da CATÁSTROFE NATURAL/ACIDENTE GEOGRÁFICO. Também recorre à reformulação das metáforas culturalmente marcadas, negando o papel efetivo da ficção ou da religião para lidar com a pandemia (LIDAR COM A COVID-19 É NÃO FICÇÃO; LIDAR COM A COVID-19 É NÃO RELIGIÃO). Porém, na ótica do primeiroministro português também já se vislumbra "uma luz ao fundo do túnel", em face dos últimos desenvolvimentos da vacina para a COVID-19.

\section{REFERÊNCIAS}

ABC NEWS. United Kingdom reaches 50,000 COVID-19 deaths on Remembrance Day, Boris Johnson says every death a 'tragedy', 2020. Disponível em: 
www.abc.net.au/news/2020-11-12/uk-reaches-50000-covid-19-deaths-on-remembranceday/12874800. Acedido em: 27 nov. 2020.

ALMEIDA, M. C. et al. Jogar Futebol com as Palavras. Imagens metafóricas no jornal A Bola. Lisboa: Colibri, 2013.

CHARTERIS-BLACK, J. Corpus approaches to critical metaphor analysis, Basingstoke: Palgrave Macmillan, 2004.

CHARTERIS-BLACK, J. Metaphors of Brexit. No cherries on the cake?, Basingstoke: Palgrave Macmillan, 2019.

CHARTERIS-BLACK, J. Politicians and Rhetoric. The persuasive power of metaphor, Basingstoke: Palgrave Macmillan, 2005.

CORREIO DA MANHÃ, 2020. Disponível em: https://www.cmjornal.pt/sociedade/detalhe/o-surto-nao-desapareceu-por-milagremarcelo-rebelo-de-sousa-deixa-alerta-sobre-coronavirus. Acedido em: 17 nov. 2020.

EXPRESS. OLIPHANT, VICKIIE. Boris Johnson speech in FULL - PM gives coronavirus update as lockdown easing SCRAPPED, 2020. Disponível em: www.express.co.uk/news/politics/1316920/Boris-Johnson-speech-in-FULL coronaviruslive-updates-lockdown-rules. Acedido em: 28 nov. 2020.

GEIRINHAS, R. A Comunicação Política Multimodal dos Presidentes da República Portuguesa (1976-2020): abordagem cognitiva e retórico-argumentativa. 2020. Tese. (Doutorado em Estudos de Cultura) Faculdade de Letras, Universidade de Lisboa, Lisboa.

GIBBS, R.W. The allegorical character of political metaphors. Discourse, Metaphor and the Social World, Amsterdam, v. 5, n. 2, p. 264-282, 2015.

GIBBS, R.W. The Embodied and Discourse Views of Metaphor: Why these are not so different and how they can be brought closer together. In: HAMPE, B. Metaphor. Embodied Cognition and Discourse, Cambridge/N.Y.: Cambridge University Press, 2017. p. 319-334.

HIDALGO-DOWNING, L.; KRALJEVIC-MUJIC, B. Infectious diseases are sleeping monters: conventional and culturally adapted new metaphors in a corpus of abstracts on immunology. IBÉRICA, Madrid, n. 17, p. 61-82, 2009.

LAKOFF, G.; JOHNSON, M. Metaphors we live by, Chicago: The University of Chicago Press, 1980.

NEHLICH, B.; KOTEYKO, N. MRSA. Portrait of a Superbug: A Media Drama in Three Acts. In: MUSOLFF, A.; ZINKEN, J. (Eds.), Metaphor and Discourse, Basingstoke: Palgrave Macmillan, 2009. p. 153-172. 
PÚBLICO,

2020.

Disponível

em:

https://www.publico.pt/2020/08/31/politica/noticia/recuperar-pais-serao-necessariosconsensos-apela-antonio-costa-1929820. Acedido em: 28 nov. 2020.

SABUCEDO, J. M. et. al. COVID-19 and the metaphor of war. International Journal of Social Psychology, v.35, n. 3, p. 618-624, 2020.

SEMINO, E. Metaphors in Discourse, Cambridge/N.Y: Cambridge University Press, 2008.

SEMINO, E. Not soldiers but fire-fighters"-metaphors and COVID-19". Health Communication, v. 36, n. 1, p. 50-58, 2020.

SIC NOTÍCIAS, 2020. Disponível em: https://sicnoticias.pt/especiais/coronavirus/202011-16-Covid-19.-Costa-diz-que-ha-luz-ao-fundo-do-tunel-so-nao-sabemos-a-extensaodo-tunel. Acedido em: 20 de nov. 2020.

THE GUARDIAN. RALINSON, KEVIN. Bugles, shootouts, trains? Covid vaccine hopes prompt strained analogies, 2020. Disponível em: www.theguardian.com/politics/2020/nov/09/bugles-shootouts-trains-covid-vaccinehopes-prompt-strained-analogies. Acedido em: 27 nov. 2020.

THE SUN. SHANIQUE, JOSEPH. Boris Johnson speech today: What did the PM's announcement reveal?, 2020. Disponível em: www.thesun.co.uk/news/11926899/borisjohnson-announcement-speech-lockdown-rules-update/. Acedido em: 27 nov. 2020.

VISÃO, 2020. Disponível em: https://visao.sapo.pt/atualidade/economia/2020-03-23covid-19-costa-conta-fechar-em-breve-acordo-com-a-banca-para-moratoria-nopagamento-de-creditos/. Acedido em: 20 nov. 2020.

Nota do editor:

Artigo submetido para avaliação em: 30 de novembro de 2020.

Aprovado em sistema duplo cego em: 07 de fevereiro de 2021. 